\title{
Tıbbi Adaçayı (Salvia officinalis L.)'nda Klon Seleksiyonu ile Geliştirilmiş B-Klonlarının Tarımsal ve Teknolojik Özellikleri
}

\author{
Ümmü TUĞLU1 ${ }^{(1)}$, Hasan BAYDAR ${ }^{* 2}$ (]) \\ 1,2Isparta Uygulamalı Bilimler Üniversitesi, Tarım Bilimleri ve Teknolojileri Fakültesi, Tarla Bitkileri Bölümü, \\ 32260, Isparta, Türkiye
}

(Alınış / Received: 18.01.2019, Kabul / Accepted: 24.07.2019, Online Yayınlanma / Published Online: 30.08.2019)

\author{
Anahtar Kelimeler \\ Tibbi adaçayı, \\ Salvia officinalis L., \\ Klon seleksiyonu, \\ B-klonları, \\ Drog verimi, \\ Uçucu yağ bileşenleri
}

\begin{abstract}
Özet: Bu araştırma, tıbbi adaçayı (Salvia officinalis L.)'nda klon seleksiyonu ile elde edilmiş 60 adet A-klonu arasından seçilmiş 10 adet B-klonu ve 1 adet standart çeşidin (Extracta) tarımsal ve teknolojik özelliklerinin belirlenmesi amacıyla yürütülmüştür. Tesadüf blokları deneme deseninde üç tekerrürlü olarak kurulan tarla denemesinde her bir B klonunda taze herba verimi $(\mathrm{kg} / \mathrm{da})$, drog herba verimi $(\mathrm{kg} / \mathrm{da})$, drog yaprak verimi $(\mathrm{kg} / \mathrm{da})$, drog yaprak oranı $(\%)$, uçucu yağ oranı (\%) ve uçucu yağ bileşenleri (\%) tespit edilmiştir. Tıbbi adaçayında taze herba verimi $701 \mathrm{~kg} / \mathrm{da}$ (14. klon) ve $1285.7 \mathrm{~kg} / \mathrm{da}$ (41. klon), drog herba verimi $176.1 \mathrm{~kg} / \mathrm{da}$ (27. klon) ve $368.8 \mathrm{~kg} / \mathrm{da}$ (8. klon), drog yaprak verimi $89 \mathrm{~kg} / \mathrm{da}$ (27. klon) ve $202.3 \mathrm{~kg} / \mathrm{da}$ (41. klon), drog yaprak oranı \%43.9 (35. klon) ve \%58.6 (41. klon), uçucu yağ oranı \%0.90 (27. klon) ve \%1.72 (8. klon) arasında değişim göstermiștir. Tıbbi adaçayı klonlarının uçucu yağ kompozisyonunu olușturan en önemli bileșenlerin 1,8-sineol (\%16.48-33.86), $\alpha$-tuyon (\%1.85-31.01), $\beta$-tuyon (\%3.99-17.51) ve kafur (\%0.74-14.94) olduğu belirlenmiş̧tir. Elde edilen sonuçlara göre drog yaprak verimi, uçucu yağ oranı ve uçucu yağ kalitesi yüksek olan 8,11 , 21 ve 41 nolu klonların tıbbi adaçayı çeşit geliştirme ıslahında öncelikli olarak değerlendirilebileceği öngörülmüştür.
\end{abstract}

\section{Agronomic and Technological Properties of B-Clones Developed by Clonal Selection of Common Sage (Salvia officinalis L.)}

\section{Keywords}

Common sage,

Salvia officinalis L.,

Clonal selection,

B-clones,

Drug yield,

Essential oil compounds

\begin{abstract}
This research was carried out to determine the agricultural and technological properties of $10 \mathrm{~B}$-clones selected from $60 \mathrm{~A}$-clones derived from the clone selection together with standard variety (Extracta) in common sage (Salvia officinalis L.). The experiment was laid out in a randomized complete block design with three replications. In each B clone, fresh herb yield $(\mathrm{kg} / \mathrm{da})$, drug herb yield $(\mathrm{kg} / \mathrm{da})$, drug leaf yield $(\mathrm{kg} / \mathrm{da})$, drug leaf ratio (\%), essential oil ratio (\%), and essential oil compounds (\%) were investigated. Fresh herb yield between 701 $\mathrm{kg} / \mathrm{da}$ (Clone 14) and $1285.7 \mathrm{~kg} / \mathrm{da}$ (Clone 41), drug herb yield between 176.1 $\mathrm{kg} / \mathrm{da}$ (Clone 27) and $368.8 \mathrm{~kg} / \mathrm{da}$ (Clone 8), drug leaf yield between $89 \mathrm{~kg} / \mathrm{da}$ (Clone 27) and $202.3 \mathrm{~kg} / \mathrm{da}$ (Clone 41), drug leaf ratios between $43.9 \%$ (Clone 35) and 58.6 (Clone 41), essential oil ratio between $0.90 \%$ (Clone 27) and $1.72 \%$ (Clone 8) were changed in the common sage clones. The most important essential oil compounds of the clones were determined as 1,8-cineole (16.48-33.86\%), $\alpha$ thujone $(1.85-31.01 \%), \beta$-thujone $(3.99-17.51 \%)$ and camphore $(0.74-14.94 \%)$. According to the results obtained, it was decided that the clones 8, 11, 21 and 41 would be considered to be priority in common sage breeding with their high drug yield, volatile oil ratio and high volatile oil quality.
\end{abstract}

\section{Giriş}

Türkiye, tıbbi ve aromatik bitkiler bakımından dünyanın en zengin ülkelerinden birisidir. Türkiye florasinda 154 familya ve 1.220 cinse ait toplam
9.753 tür doğal olarak yayılış göstermektedir. Türkiye florasını değerli kılan diğer önemli bir özelliği de çok sayıda endemik takson içermesidir. Ülkemizdeki endemik bitki takson sayısı 3.649, endemizm oranı ise \%31.8'dir [1]. Endemikler başta 
olmak üzere Türkiye bitkilerinin tıbbi ve aromatik değeri çok yüksektir. Bu nedenle Anadolu, geleneksel tıp uygulamaları ve modern tıp bilimi için çok zengin bir etnobotanik araştırma kaynağıdır. Türkiye'de 500-1000 arasında bitki türünden halk hekimliği veya geleneksel tıp uygulamaları kapsamında faydalanıldığı, doğadan toplanarak iç ve dış ticareti yapılan 347 kadar tür bulunduğu ve bunlardan da \%30’unun dış ticareti yapıldığı bildirilmiştir [2].

Türkiye'de hem doğadan yabani olarak toplanarak hem de tarım alanlarında kültürü yapılarak üretilen en değerli tıbbi ve aromatik bitkilerden birisi de adaçayıdır. Adaçayı (Salvia), Lamiaceae (Labiatea) familyasından olup dünyada 900'ün üzerinde türü yayılış göstermektedir. Ancak ticari değeri en yüksek olan türler tıbbi adaçayı (Salvia officinalis L.), Anadolu adaçayı ( $S$. fruticosa Mill., syn. S. triloba L.), elma adaçayı ( $S$. pomifera L.), Ispanyol adaçayı ( $S$. lavandulaefolia Vahl.) ve misk adaçayı (S. sclarea L.)'dır [3]. Türkiye florasında Salvia genusuna ait \%51'i endemik olan toplam 97 tür doğal yayılıș göstermektedir [4]. Bunlar arasında tıbbi adaçayı ( $S$. officinalis L.) yer almamaktadır. Bunun yerine bilhassa Akdeniz ikliminin etkili olduğu bölgelerimizde "Anadolu adaçayı" olarak adlandırılan S. fructicosa türü ile "şalba/çalba" olarak adlandırılan ve $S$. tomentosa türleri doğadan yoğun olarak toplanmaktadır [5].

Tıbbi ve aromatik bitkilerden üretici ve tüketici taleplerine göre yüksek verimlilik ve kalitede üretim yapılabilmesi için her şeyden önce ıslah edilerek geliştirilmiş çeşitlerine ve standartlara uygun tohumluk materyaline ihtiyaç vardır [6]. Yabancı tozlaşıp döllenen, hem generatif hem de vejetatif olarak üretilebilen tıbbi adaçayının da çeşit ıslahında "klon seleksiyonu" metodunun oldukça başarılı ve etkili bir ıslah yöntemi olduğu açıklanmıştır [7].

Tıbbi adaçayı ıslahı üzerinde yapılan çalışmalara bakıldığında, yetiştiriciliği için yüksek drog yaprak verimi üreten, yüksek oranda uçucu yağ içeren ve uçucu yağ bileşenleri uluslararası standartlara uygun olan çeşitlerin geliştirilmesinin temel alındığı görülmektedir. Bu araştırmada, tıbbi adaçayı (Salvia officinalis L.) populasyonundan klon seleksiyonu ile elde edilmiş 60 adet A-klonu arasından seçilmiş 10 adet B-klonunun tarımsal ve teknolojik özelliklerinin belirlenmesi amaçlanmıştır.

\section{Materyal ve Metot}

$\mathrm{Bu}$ araştırmanın tarla denemesi 2017 yılında Isparta ili (3750' K ve 30³2' D, 1008 m) Süleyman Demirel Üniversitesi Ziraat Fakültesi Tarla Bitkileri Bölümünde yürütülmüştür. Deneme tarlası toprağı; tekstür bakımından killi-kalkerli, alkali (pH 8.1), katyon değişim kapasitesi \%36 ve toplam tuz içeriği $\% 0.025$ olan, kireççe zengin (\%25.5), alınabilir fosfor $\left(3.55 \mathrm{~kg} / \mathrm{da} \mathrm{P}_{2} \mathrm{O}_{5}\right)$ bakımından fakir, potasyum bakımından zengin $\left(75.4 \mathrm{~kg} / \mathrm{da} \mathrm{K}_{2} 0\right)$ ve organik madde bakımından fakir (\%1.34) olup yarayışlı nem (\%8.35) bakımından da yetersiz bir topraktır. Tıbbi adaçayı bitkisi özellikle kireççe zengin ve alkali topraklarda çok iyi gelişme gösterdiğinden deneme alanı toprağı adaçayı tarımı için oldukça uygundur.

Çalışmada materyal olarak açıkta tozlaşma ürünü olan tıbbi adaçayı (Salvia officinalis L.) populasyonu tohumları kullanılmıştır. Tohumlar, SDÜ Ziraat Fakültesi Araştırma Uygulama Çiftliği'nde 4 Nisan 2005 tarihinde örtü altında torf içeren multipodlara ekilmiş ve sağlıklı gelişen toplam 600 fide araștırma tarlasına $100 \times 50 \mathrm{~cm}$ sıklıkla dikilmiştir. 2010 yılına kadar düzenli bakım işlemleri yapılmış ve fenolojik gözlem altında tutulmuşlardır. Büyüme ve gelişme özellikleri ile morfolojik karakterleri yönüyle bitkiler arasında geniş bir fenotipik ve genotipik varyasyon olduğu gözlenmiştir. $\mathrm{Bu}$ varyasyonun içinden tarımsal değeri yüksek olduğu düşünülen 60 bitki klon anacı olarak etiketlenmiştir. Her bir klon anacının kök tacı bölgesinden sökülerek alınan 12 köklü sürgün 23 Nisan 2010 tarihinde 100x50 cm sıklıkta dikilerek klon hattı sıraları oluşturulmuştur. Böylece açıkta tozlaşarak elde edilmiş adaçayı populasyonundan seçilmiș 60 klon hattına (Aklonları) ait toplam 720 bitkiden oluşan bir deneme tarlası kurulmuştur.

A-klonları arasında, drog yaprak verimi, uçucu yağ oranı ve uçucu yağ kalitesi yüksek olan 10 adet Bklonu $(3,8,11,14,21,26,27,35,41$ ve 51 nolu klonlar) belirlenmiş, bu klonların B-klonları olarak seçilip tekerrürlü verim denemelerine alınmasına karar verilmiştir [7].

Bu araştırmada, 3, 8, 11, 14, 21, 26, 27, 35, 41 ve 51 nolu 10 adet B-klonu ile kontrol çeşit olarak KÜTAŞ Tarım Ürünleri ve Dıș Ticaret A.Ş.'den temin edilen ve bu firma tarafından Ege Bölgesi'nde sözleşmeli olarak üretimi yaptırılan Extracta tıbbi adaçayı çeşidi (Johnny Seed Company, USA) kullanılmıştır. 5 Mayıs 2013 tarihinde tesadüf blokları deneme desenine göre 3 tekerrürlü olarak oluşturulmuş deneme parselleri üzerine $100 \times 50 \mathrm{~cm}$ siklıkta dikim yapılmıștır. Dikim materyali olarak A-klonlarının ve kontrol (standart) çeşidin köklü sürgünleri kullanılmıştır. Her bir tekerrürde her bir deneme parseli $6 \mathrm{~m}$ uzunluğunda olup, her bir parselde her bir klon 12 bitki ile temsil edilmiștir. Deneme alanının en dış iki kenarına ayrıca kenar tesiri olarak standart çeșit yerleștirilmiştir. Böylece, her bir tekerrürde birer sıralık parsellerde 10 adet B-klonu ve 1 adet standart çeşit rastgele dağıtılmıştır.

B-klonlarının yer aldığı deneme tarlası düzenli olarak yabancl otlardan temizlenmiş ve yaz mevsiminde aşırı kurak ve sıcak geçen günlerde damlatıcı borular yardımıyla sulama yapılmıştır. Çalışmada spontan melez tıbbi adaçayı populasyonundan klon seleksiyonu yöntemi ile geliștirilmiş 10 adet Bklonunun 2017 yılı yetişme sezonunda tarımsal ve teknolojik özellikleri belirlenmiştir. Klonlar \%50 
çiçeklenme devresinde toprak yüzeyinden $15 \mathrm{~cm}$ yukarıdan biçilerek hasat edilmişlerdir. Biçilen taze herba kurutma rafları üzerinde oda koşullarında kurutulmuş ve kuru herbada saplar ve yapraklar birbirinden ayrlarak drog yapraklar elde edilmiştir. Böylece her bir B-klonunda kenar tesiri dışında kalan 10 bitkide taze herba verimi $(\mathrm{kg} / \mathrm{da})$, drog herba verimi (kg/da), drog yaprak verimi (kg/da), drog yaprak oranı (\%) belirlenmiştir.

Her bir klona ait tıbbi adaçayı yaprakları kurutulduktan sonra içerdikleri uçucu yağ oranları belirlenmiştir. Uçucu yağ elde etmek için Clevenger tipi hidro-distilasyon cihazında 3 saat süreyle damıtma işlemi yapılmış, elde edilen uçucu yağların miktarları ml olarak ölçülerek \% oranları (v/w) belirlenmiştir.

Her bir klon hattını temsil eden uçucu yağ numuneleri GC-MS (Gas Chromatography-Mass Sectrometry) cihazında analiz edilerek uçucu yağ bileșenleri ve oranları belirlenmiștir. Cihaz: QP-5050 GC/MS, Kapiler kolon: CP-Wax 52 CB (50 m x 0.32 $\mathrm{mm}, 0.25 \mu \mathrm{m})$, Firın sıcaklık programı: dakikada $10^{\circ} \mathrm{C}$ artarak $60^{\circ} \mathrm{C}^{\prime}$ den $220^{\circ} \mathrm{C}$ 'ye ulaşılmış ve $220^{\circ} \mathrm{C}$ 'de 10 dakika beklemiştir; Toplam koșturma süresi: 60 dakika, Enjektör sıcaklığı: $240^{\circ} \mathrm{C}$, Detektör sıcaklığı: $250^{\circ} \mathrm{C}$, Taşıyıcı gaz: He (20 ml/dak.).

\subsection{Verilerin değerlendirilmesi}

Elde edilen veriler tesadüf blokları deneme deseninde 3 tekerrürlü olarak varyans analizi yapılmış ve incelenen özelliklere ilişkin ortalamalar arasındaki istatistiksel farklılıklar Duncan çoklu karşılaștırma testi ile belirlenmiştir.

\section{Bulgular ve Tartışma}

Tıbbi adaçayı klonlarına ait taze herba, drog herba ve drog yaprak verimleri ile drog yaprak oranı ve uçucu yağ oranına ilişkin varyans analizi Tablo 1'de sunulmuştur. Varyans analiz sonuçlarına göre taze herba, drog herba ve drog yaprak verimleri ile uçucu yağ oranı arasındaki farklılıklar istatistiksel olarak $\% 1$ ( $\mathrm{p}<0.01)$, drog yaprak oranı \%5 $(\mathrm{p}<0.05)$ seviyesinde önemli bulunmuștur (Tablo 1).

Tıbbi adaçayı klonları 2017 yılında 20 Mayıs tarihinden itibaren çiçeklenmeye başlamışlar, bu ay sonuna kadar \%50 çiçeklenmelerini tamamlayarak hasat (biçim) dönemine girmişlerdir. Klonların çiçeklenme tarihleri dikkate alındığında bütün klonların Extracta çeşidinden daha erken ilk ve tam çiçeklenme tarihine ulaştıkları tespit edilmiştir. Çiçeklenme tarihi itibariyle 35, 11, 21, 26, 27 ve 8 nolu klonlar daha erken 3, 41 ve 51 numaralı klonlar daha geç çiçeklenmeye başlamışlardır.

Tıbbi adaçayı klonlarında taze herba verimi 701.0 $\mathrm{kg} / \mathrm{da}$ (14 nolu klon) ve $1285.7 \mathrm{~kg} / \mathrm{da}$ (41 nolu klon) arasinda (ortalama $990 \mathrm{~kg} / \mathrm{da}$ ), drog herba verimi $176.1 \mathrm{~kg} / \mathrm{da}$ (27 nolu klon) ve $368.8 \mathrm{~kg} / \mathrm{da}$ (8 nolu klon) arasında (ortalama $292.1 \mathrm{~kg} / \mathrm{da}$ ), drog yaprak verimi $89.0 \mathrm{~kg} /$ da (27 nolu klon) ve $202.3 \mathrm{~kg} / \mathrm{da}$ (41 nolu klon) arasinda (ortalama $156.6 \mathrm{~kg} / \mathrm{da}$ ), drog yaprak oranı \%43.9 (35 nolu klon) ve \%58.6 (41 nolu klon) arasında (ortalama \%51.9) değişim göstermiștir. Drog yaprak verimi bakımından 14 ve 35 nolu klonlar dışındaki klonların tamamı Extracta çeşidinden daha yüksek ortalama değerlere sahip olmuşlardır (Tablo 2).

Dünyada ticari değeri yüksek tıbbi adaçayı çeşitlerinde uçucu yağ oranının en az \%1.5, mümkünse \%2'nin üzerinde olması istenmektedir. Bu kapsamda araştırmada \%1.5'dan daha fazla uçucu yağ içerdikleri tespit edilen $8,11,14,21,41$ ve 51 numaralı klonlar olarak belirlenmiștir. Klonlar arasında en düşük uçucu yağ oranı \%0.90 ile 27 numaralı klonda, en yüksek uçucu yağ oranı \%1.72 ile 8 numaralı klonda tespit edilmiştir (Tablo 2).

Bir uçucu yağın karakteristik kokusunu kendisini meydana getiren koku molekülerinin kompozisyonu belirler. Bu kompozisyon aynı zamanda uçucu yağın kalitesiyle doğrudan ilişkilidir. Tıbbi adaçayı uçucu yağı bașlıca asiklik, monosiklik ve bisiklik karbon iskeletlerinden oluşan monoterpenlerden oluşmaktadır. GC-FID/MS analizlerine göre tıbbi adaçayı klonlarının uçucu yağlarında toplam 31 farklı bileșen tespit edilmiştir. $\mathrm{Bu}$ bileșenler arasında özellikle 1,8-sineol (\%16.48-33.86), $\alpha$-tuyon (\%1.85$31.01)$, $\beta$-tuyon (\%3.99-17.51) ve kafur $(\% 0.74-$ 14.94) yüksek oranlarda bulunan ve kalite üzerine fazla olan bileşenlerdir. Tıbbi adaçayı yağının antibakteriyal, antifungal ve antioksidan etkisini de daha çok bunlar arttırmaktadır [8]. Ancak tuyonların insanlarda hem beyin hem de ciğer hücreleri üzerinde toksik etkisi olabileceği, özellikle $\alpha$-tuyonun, $\beta$-tuyona göre daha toksik olduğu rapor edilmiștir [9]. Bununla birlikte iyi kalitede tıbbi adaçayı yağının olabildiğince yüksek oranlarda $\alpha+\beta$-tuyon $(>\% 50)$ ve olabildiğince düşük oranda kafur $(<\% 20)$ içermesi gerektiğini rapor etmişlerdir [10].

Tablo 1. Tıbbi adaçayı klonlarına ait taze herba, drog herba ve drog yaprak verimleri ile drog yaprak oranı ve uçucu yağ oranına ilișkin varyans analiz tablosu

\begin{tabular}{lccccccccccc}
\hline \multirow{2}{*}{ VK } & SD & \multicolumn{2}{c}{$\begin{array}{c}\text { Taze herba } \\
\text { verimi }\end{array}$} & \multicolumn{2}{c}{$\begin{array}{c}\text { Drog herba } \\
\text { verimi }\end{array}$} & \multicolumn{2}{c}{$\begin{array}{c}\text { Drog yaprak } \\
\text { verimi }\end{array}$} & \multicolumn{2}{c}{$\begin{array}{c}\text { Drog yaprak } \\
\text { oranı }\end{array}$} & \multicolumn{2}{c}{$\begin{array}{c}\text { Uçucu yağ } \\
\text { oranı }\end{array}$} \\
\cline { 3 - 12 } & & HKO & F & HKO & F & HKO & F & HKO & F & HKO & F \\
\hline Tekerrürler & 2 & 43.0 & 0.0 & 1979.4 & 0.9 & 12.3 & 0.03 & 21.2 & 1.2 & 0.03 & 2.8 \\
Klonlar & 10 & 109218.7 & $10.9^{* *}$ & 10753.3 & $5.2^{* *}$ & 4411.2 & $10.0^{* *}$ & 40.9 & $2.4^{*}$ & 0.27 & $19.7^{* *}$ \\
Hata & 20 & 9948.9 & & 2069.4 & & 438.0 & & 16.9 & & 0.01 &
\end{tabular}

VK: Varyasyon Kaynakları, SD: Serbestlik Derecesi, HKO: Hata Kareler Ortalaması, F: F değeri , ${ }^{*} \mathrm{P}<0.05,{ }^{* *} \mathrm{P}<0.01$ 
Tablo 2. Tıbbi adaçayı klonlarına ait taze herba, drog herba ve drog yaprak verimleri ile drog yaprak oranı ve uçucu yağ oranına ilișkin ortalama değerler ve oluşan Duncan önemlilik grupları

\begin{tabular}{lccccc}
\hline Klonlar & $\begin{array}{c}\text { Taze herba verimi } \\
(\mathbf{k g} / \mathbf{d a})\end{array}$ & $\begin{array}{c}\text { Drog herba verimi } \\
\mathbf{( k g / d a )}\end{array}$ & $\begin{array}{c}\text { Drog yaprak } \\
\text { verimi (kg/da) }\end{array}$ & $\begin{array}{c}\text { Drog yaprak } \\
\text { oranı (\%) }\end{array}$ & $\begin{array}{c}\text { Uçucu yağ } \\
\text { oranı (\%) }\end{array}$ \\
\hline 3 & $1188.5 \mathrm{ab} *$ & $337.8 \mathrm{ab}$ & $183.4 \mathrm{abc}$ & $54.1 \mathrm{ab}$ & $1.14 \mathrm{~cd}$ \\
8 & $1137.5 \mathrm{abc}$ & $368.8 \mathrm{a}$ & $195.1 \mathrm{ab}$ & $54.0 \mathrm{ab}$ & $1.72 \mathrm{a}$ \\
11 & $995.1 \mathrm{cde}$ & $306.6 \mathrm{abc}$ & $157.1 \mathrm{bcd}$ & $51.2 \mathrm{abc}$ & $1.68 \mathrm{a}$ \\
14 & $701.0 \mathrm{~g}$ & $221.3 \mathrm{~cd}$ & $118.0 \mathrm{efg}$ & $49.9 \mathrm{bc}$ & $1.70 \mathrm{a}$ \\
21 & $1144.4 \mathrm{abc}$ & $362.7 \mathrm{a}$ & $200.4 \mathrm{a}$ & $50.4 \mathrm{bc}$ & $1.50 \mathrm{ab}$ \\
26 & $929.4 \mathrm{def}$ & $293.3 \mathrm{abc}$ & $153.7 \mathrm{cde}$ & $52.6 \mathrm{ab}$ & $1.33 \mathrm{bc}$ \\
27 & $757.0 \mathrm{fg}$ & $176.1 \mathrm{~d}$ & $89.0 \mathrm{~g}$ & $50.8 \mathrm{abc}$ & $0.90 \mathrm{e}$ \\
35 & $840.0 \mathrm{efg}$ & $258.0 \mathrm{bcd}$ & $113.0 \mathrm{fg}$ & $43.9 \mathrm{c}$ & $1.05 \mathrm{de}$ \\
41 & $1285.7 \mathrm{a}$ & $330.1 \mathrm{ab}$ & $202.3 \mathrm{a}$ & $58.6 \mathrm{a}$ & $1.50 \mathrm{ab}$ \\
51 & $843.4 \mathrm{efg}$ & $253.9 \mathrm{bcd}$ & $139.0 \mathrm{def}$ & $54.8 \mathrm{ab}$ & $1.52 \mathrm{a}$ \\
Kontrol (Extracta) & $1068.1 \mathrm{bcd}$ & $304.0 \mathrm{abc}$ & $171.5 \mathrm{a}-\mathrm{d}$ & $50.2 \mathrm{bc}$ & $1.04 \mathrm{de}$ \\
\hline
\end{tabular}

*Aynı harflerle gösterilen ortalamalar arasındaki farklar istatistiksel olarak önemli değildir.

Tıbbi adaçayı uçucu yağ bileşenlerden $\alpha$-tuyon, $\beta$ tuyon, kafur, 1,8-sineol, $\alpha$-pinen, kamfen, limonen, $\alpha$ humulen, bornil asetat, linalol ve linalil asetat tıbbi adaçayı kalite standartlarında yer alan uçucu yağ bileşenleridir. $\mathrm{Bu}$ bileşenlere ilişkin kalite standardının alt ve üst sınır değerleri Tablo 3'te verilmiș ve bu sınır değerlerine uygunluk gösteren klonlar belirtilmiştir. ISO 9909 (1997)'a göre tıbbi adaçayı uçucu yağındaki bileşenlerin $\alpha$-tuyon \%18.043.0, $\beta$-tuyon \%3.0-8.5, kafur \%4.5-24.5, 1,8-sineol \%5.5-13.0, kamfen \%1.5-7.0, limonen \%0.5-3.0, $\alpha-$ humulen <\%12.0, $\alpha$-pinen \%1.0-6.5, bornil asetat < $\% 2.5$ ve linalol + linalil asetat $<\% 1.0$ değerlerinde bulunması gerektiği belirtilmiştir [11].

ISO standartları temel alındığında $\alpha$-pinen bileşeninin bulunduğu \%1 alt sınır ve \%6.5 üst sınırında bütün klonlar ve kontrol çeşit uygunluk göstermiştir. Kamfen bileşeni için \%1.5-7.0 aralığında yedi klon (8, $11,14,21,26,41$, ve 51) ve kontrol çeşit yer alırken, limonen bileşeni için \%0.5-3.0 aralığında altı klon (3, $8,21,27,35$ ve 51) yer almıştır. 1,8-sineol bileşeni bakımından bütün klonlar \%13 üst sınırından daha yüksek değerler vermiştir. $\alpha$-tuyon bileşeninin bulunduğu \%18.0-43.0 sinırında sadece iki klon (3 ve 35 nolu klonlar) yer almaktadırlar. $\beta$-tuyon için \%3.08.5 aralığında sekiz klon $(3,8,11,14,21,26,41,51$ nolu klonlar) ve kontrol çeşit bulunmaktadır. Kafur bileşeni için sınır aralığı olan \%4.5-24.5 arasında ise 27 numaralı klon haricince diğer klonlar ve kontrol çeşit yer almaktadır. Bornil asetat için belirtilen \%02.5 aralığına üç klon $(27,41,51$ nolu klonlar) ve kontrol çeşit bulunurken, $\alpha$-humulen bileșeni için \%0.0-12.0 aralığında kontrol ile birlikte dokuz klon $(3,8,11,14,21,26,35,41,51)$ bulunmuștur. Linalol + linalil asetat için belirtilen \%0-1.0 aralığına bütün klonlar uygunluk göstermiștir (Tablo 3).

Tıbbi adaçayı uçucu yağ bileşenlerinden alfa ve beta tuyonlar (+)-sabinene sentaz ile sabinen üzerinden sentezlenirken, 1,8-sineol doğrudan 1,8-sineol sentaz tarafından üretilmektedir. Diğer yandan (+)-bornil difosfat sentaz tarafından üretilen bornil difosfat hidrolize edilerek borneol ve sonra okside edilerek kafur üretilmektedir [12]. İşte spesifik uçucu yağ moleküllerinin sentezinden sorumlu genlere ve ilgili enzimlere bağlı olarak tıbbi adaçayında farklı kemotipler ortaya çıkabilmektedir.

Tablo 3. Tıbbi adaçayından elde edilen uçucu yağların klonlara göre içerik değerleri*

\begin{tabular}{|c|c|c|c|c|c|c|c|c|c|c|c|c|c|c|}
\hline \multirow{2}{*}{ Bileşenler } & \multicolumn{2}{|c|}{ IS0 (9909) } & \multicolumn{11}{|c|}{ Klonlar } & \multirow{2}{*}{$\begin{array}{c}\text { ISO'ya } \\
\text { uyumlu klon } \\
\text { sayısı } \\
\end{array}$} \\
\hline & Alt & Üst & 3 & 8 & 11 & 14 & 21 & 26 & 27 & 35 & 41 & 51 & $\mathbf{K}$ & \\
\hline$\alpha$-pinen & 1 & 6.5 & 5.4 & 3.8 & 3.8 & 3.8 & 4.6 & 4.5 & 4.6 & 5.0 & 3.6 & 4.7 & 4.1 & 10 \\
\hline Kamfen & 1.5 & 7 & 0.9 & 3.7 & 3.5 & 3.1 & 3.8 & 3.9 & 1.4 & 1.4 & 3.2 & 3.8 & 3.4 & 7 \\
\hline limonen & 0.5 & 3 & 1.4 & 1.2 & 0.0 & 0.0 & 1.2 & 0.0 & 1.3 & 1.5 & 0.0 & 1.8 & 0.0 & 6 \\
\hline 1.8-sineol & 5.5 & 13 & 21.0 & 32.0 & 32.7 & 32.2 & 33.8 & 33.7 & 16.4 & 17.0 & 32.6 & 26.9 & 29.4 & 0 \\
\hline$\alpha$-tuyon & 18 & 43 & 31.0 & 14.4 & 13.8 & 10.8 & 13.0 & 14.2 & 1.8 & 21.7 & 12.9 & 10.7 & 12.1 & 2 \\
\hline$\beta$-tuyon & 3 & 8.5 & 6.9 & 4.8 & 4.4 & 4.0 & 4.4 & 4.9 & 17.5 & 10.0 & 4.6 & 3.9 & 4.8 & 8 \\
\hline Kafur & 4.5 & 24.5 & 5.0 & 14.9 & 13.6 & 12.9 & 12.9 & 12.7 & 0.7 & 6.5 & 14.1 & 9.5 & 12.0 & 9 \\
\hline Bornil asetat & 0 & 2.5 & 0.0 & 0.0 & 0.0 & 0.0 & 0.0 & 0.0 & 0.6 & 0.0 & 0.5 & 0.8 & 0.8 & 3 \\
\hline$\alpha$-humulen & 0 & 12 & 3.4 & 0.8 & 0.9 & 2.0 & 1.0 & 0.6 & 15.0 & 5.9 & 1.3 & 2.1 & 1.8 & 9 \\
\hline $\begin{array}{l}\text { Linalool } \\
+ \text { Linalil asetat }\end{array}$ & 0 & 1 & 0.0 & 0.0 & 0.0 & 0.0 & 0.0 & 0.0 & 0.0 & 0.0 & 0.0 & 0.0 & 0.0 & 10 \\
\hline
\end{tabular}

*ISO 9909'a göre tıbbi adaçayı uçucu yağında standartları belirtilen bileşenler verilmiştir. K: Kontrol (Extracta) 
Örneğin Makedonya'da tıbbi adaçayl populasyonlarında monoterpenlerden kafur (\%13.15-25.91), $\alpha$-tuyon (\%19.25-26.33), $\beta$-thujone $(\% 2.03-5.28), \quad 1,8$-sineol $(\% 6.51-13.60), \alpha$-pinen (\%.93-1.47) ve borneol (\%1.07-4.67) bakımından geniş bir varyasyon olduğunu, bazı populasyonların kafur, bazlarının ise tuyon tipi kemotipler barındırdığını rapor etmişlerdir [13]. Bizim araştırmamızda da ilgili bileşenler bakımından aynı popülasyondan seçilerek klonal çoğaltılan tıbbi adaçayı klonlarıdan bazılarının kemotip olduğu anlaşılmaktadır. Örneğin 3 nolu klon yüksek $\alpha$-tuyon ve 27 nolu klon düșük kafur içeren kemotipler olarak dikkati çekmektedir (Tablo 3).

\section{Sonuç ve Öneriler}

Tıbbi adaçayı, Türkiye'de kültürü yapılmaya başlanan ve üretim alanları giderek genişleyen tıbbi ve aromatik bitkilerden biridir. Ancak tıbbi adaçayı yetiştiriciliğinde her şeyden önce yüksek verimlilikte ve kalitede adaçayı çeşitlerine ihtiyaç bulunmaktadır. $\mathrm{Bu}$ araştırmada, klon seleksiyonu yöntemi ile yüksek drog yaprak verimi ve standartlara uygun kalitede uçucu yağ üreten tıbbi adaçayı (Salvia officinalis L...) klonlarının geliştirilebileceği anlaşılmıştır.

Tıbbi adaçayı klonları arasında drog yaprak verimi bakımından 41, 21, 8 ve 3 nolu klonlar, uçucu yağ oranı bakımından 8, 14, 11, 51, 21 ve 41 nolu klonlar kontrol çeşitten (Extracta) daha üstün bulunmuştur. Tıbbi adaçayı klonlarında uçucu yağı oluşturan en önemli bileşenlerin 1,8-sineol, $\alpha$-tuyon, $\beta$-tuyon ve kafur olduğu tespit edilmiş, 27 nolu klon hariç diğer klonların uçucu yağları tıbbi adaçayı kalite standardına (ISO 9909:1997) büyük ölçüde uygun oldukları tespit edilmiştir.

Sonuç olarak, bu araştırmada klon seleksiyonu ile yüksek drog yaprak verimine, yüksek uçucu yağ oranına ve yüksek uçucu yağ kalitesine sahip tıbbi adaçayı klonları belirlenmiş ve bu klonlar arasında özellikle 8, 11, 21 ve 41 nolu klonların tıbbi adaçayı çeşit geliştirme ıslahında öncelikli olarak değerlendirilebileceği öngörülmüştür.

\section{Teşekkür}

Bu araștırmaya 4953-YL1-17 nolu proje olarak maddi destek sağlayan Süleyman Demirel Üniversitesi Bilimsel Araştırma Projeleri Yönetim Birimi Başkanlığına teşekkür ederiz.

\section{Kaynakça}

[1] Güner, A., Aslan, S., Ekim, T., Vural, M., Babaç, M.T. 2012. Türkiye Bitkileri Listesi (Damarlı Bitkiler). Nezahat Gökyiğit Botanik Bahçesi ve Flora Araștırma Derneği Yayını, İstanbul.
[2] Özhatay, N., Koyuncu, M., Atay, S., Byfield, A. 1997. Türkiye'nin Doğal Tıbbi Bitkilerinin Ticareti Hakkında Bir Çalıșma. Doğal Hayatı Koruma Derneği, İstanbul, Türkiye.

[3] Sage, 2000. Sage: The Genus Salvia. Kintzios, E. (Ed.), Harwood Acedemic Publishers, The Netherlands.

[4] Karık, Ü., Sağlam, C. 2017. Tekirdağ Ekolojik Koşullarında Anadolu Adaçayı (Salvia fruticosa Mill.) Popülasyonlarının Verim ve Kalite Özelliklerinin Belirlenmesi. Tarla Bitkileri Merkez Araştırma Enstitüsü Dergisi, 26(2), 203-215.

[5] Baydar, H. 2016. Tıbbi ve Aromatik Bitkiler Bilimi ve Teknolojisi (Genişletilmiş 5. Baskı). SDÜ Yayın No: 51, Isparta, 339 s.

[6] Bayram, E., Kırıcı, S., Tansı, S., Yılmaz, G., Arabacı, O., Kızıl, S., Telci, İ. 2010. Tıbbi ve Aromatik Bitkiler Üretiminin Arttırılması Olanakları. Türkiye Ziraat Mühendisliği VII. Teknik Kongresi Bildirileri, 437-456 s.

[7] Karakuş, M., Baydar, H., Erbaş, S. 2017. Tıbbi Adaçayı (Salvia officinalis L.) Populasyonundan Geliştirilen Klonların Verim ve Uçucu Yağ Özellikleri. Tarla Bitkileri Merkez Araștırma Enstitüsü Dergisi, 26, 99-104.

[8] Baydar, H., Özkan G., Erbaş S., Altındal D. 2007. Yield, Chemical Composition and Antioxidant Properties of Extracts and Essential Oils of Sage and Rosemary Depending on Seasonal Variations. International Medicinal and Aromatic Plants Conference on Culinary Herbs, 826, 383-390.

[9] Höld, K.M, Sirisoma, N.S., Ikeda, T., Narahashi, T., Casida, J.E. 2000. $\alpha$-thujone. Proceedings of the National Academy of Sciences of the United States of America, 97(8), 3826-3831.

[10] Raal, A., Orav, A., Arak, E. 2007. Composition of the Essential Oil of Salvia officinalis L. from Various European Countries. Nat. Prod. Res., 21, 406-411.

[11] ISO 9909, 1997. International Organization for Standardization. Oil of Dalmatian Sage (Salvia officinalis L.), Geneva (Switzerland).

[12] Wise, M.L., Savage, T.J. Katahira, E., Croteau, R. 1998. Monoterpene synthases from common sage (Salvia officinalis). Journal of Biological Chemistry, 273(24), 14891-14899.

[13] Stefkov, G., Cvetkovikj, I., Karapandzova, M., Kulevanova, S. 2011. Essential Oil Composition of Wild Growing Sage from R. Macedonia. Macedonian Pharmaceutical Bulletin, 57(1-2), 71-76. 